\title{
Conventional Schwannoma
}

National Cancer Institute

\section{Source}

National Cancer Institute. Conventional Schwannoma. NCI Thesaurus. Code $C 121677$.

A common, usually encapsulated benign nerve sheath tumor composed of welldifferentiated Schwann cells. 